\title{
Production Performance of Wood Flour Reinforced Polymer Composites in Extrusion Process
}

\author{
A.S. VAnli And A. AKDOGAN* \\ Yildiz Technical University, Department of Mechanical Engineering, 34349, Istanbul, Turkey.
}

\begin{abstract}
Wood flour reinforced polymer composites attract attention of the researchers and the market due to their visually aesthetic and low maintenance properties. Additive usage is an increasing application especially in wood flour reinforced polymer composite production for penetration into the new markets with more strong performance requirements and long-term stability interests. Since wood flour reinforced polymer composite materials need an efficient compounding process, extruders are specially designed as compounding types to overcome production difficulties and to supply high processing performance requirements. The experiments conducted in this work detail the steps of the production, such as process design and manufacturing and answer almost all required needs for continuous processing of wood flour reinforced polymer composite products. Higher processing capabilities and satisfactory mechanical test results were achieved with the help of pulping and compounding processes.
\end{abstract}

DOI: 10.12693/APhysPolA.134.18

PACS/topics: wood flour reinforcement, polymer composite, extrusion process, production performance

\section{Introduction}

Recently lignocellulosic material reinforcement has gained attention in the polymer production industry as a result of increasing cost of petroleum products. Polymer filler material can be obtained from various national resources such as hemp, shells of nuts, rice hulls and residual wood flour (WF). During the last two decades, these materials have been described under the term of lignocellulosic material reinforced polymer composites $[1,2]$.

The usage of such natural fibres is growing due to their strong fibre structure. For instance, wood-polymer composites are used primarily in building products such as decking, fencing, siding, windows, doors and decorative trim. Other applications are in infrastructure e.g. boardwalks, marinas; in transportation e.g. interior automotive panels, and head liners; and in industrial and consumer applications e.g. playground equipment and pallets. Outdoor tables, chairs and benches are already being made of wood polymer composites [1, 2].

Wood-polymer composite manufacturers are trying to penetrate into trim board and plywood markets, using its lightness, abrasiveness and environmental friendly specifications. In the cases of using more than $70 \%$ of lignocellulosic material in weight, the composite could be used in food packaging industry as a biodegradable product. The main drawbacks of these composites are their water sensitivity, relatively poor dimensional stability, poor fiber-matrix adhesion and original wood fiber characteristic losses in time [3-5].

Although WF reinforced composites are in general compatible with existing cost-effective processing machines, using these kinds of machines to produce WF re-

\footnotetext{
*corresponding author; e-mail: nomak@yildiz.edu.tr
}

inforced polymer composites causes some important processing problems. The primary process difficulties are high die-head pressures, high energy consumption and low mechanical and thermal efficiencies. High production costs and low productivity would probably be experienced as a result of these main difficulties. Extruders have high dispersive production areas, they require high speed mixing capability and certain chemical lubricating and bonding additives, especially for wood-polymer composite part production.

Nowadays, some certain chemical lubricating and bonding additives which can be found commercially and are designed specifically for lignocellulosic material reinforced polymer composite production are being used to overcome the partial agglomerations of the material [6-8]. Subsequently, some investigators have reported studies on the reaction of wood with a large number of alcohols to supply high processing performances. As an alternative to the conventional pulping process, solvent pulping method plays an important role, solving the lignin into the lignocellulosic structure and providing better rheological properties [9-11].

This paper approaches pulping and compounding processes for homogeneous mixing of the composite to reach high productivity and high quality product manufacturing by using a specially designed compounding extruder.

\section{Experimental work on composite production}

The basic properties of the low density pure polyethylene used for manufacturing of WF reinforced polymer composite are; $20.0 \mathrm{~g} / 10 \mathrm{~min}$. melt flow index at $190^{\circ} \mathrm{C} / 2.16 \mathrm{~kg}, 0.923 \mathrm{~g} / \mathrm{cm}^{3}$ density, $10.5 \mathrm{MPa}$ ultimate tensile strength and $50 \%$ ultimate elongation.

The additives used for the composite production are slip/anti-blocking agent (1 wt.\%) and coupling agent (1 wt.\%). The beech WF was provided from a lumber market. The filtered beech WF was processed in 
the pulping bath consisting of $10 \% \mathrm{Na}_{2} \mathrm{SO}_{3}(\mathrm{w} / \mathrm{w})$ for 25 minutes at $95^{\circ} \mathrm{C}$. Differential scanning calorimetry (DSC) diagram of the pulped beech WF is given in Fig. 1.

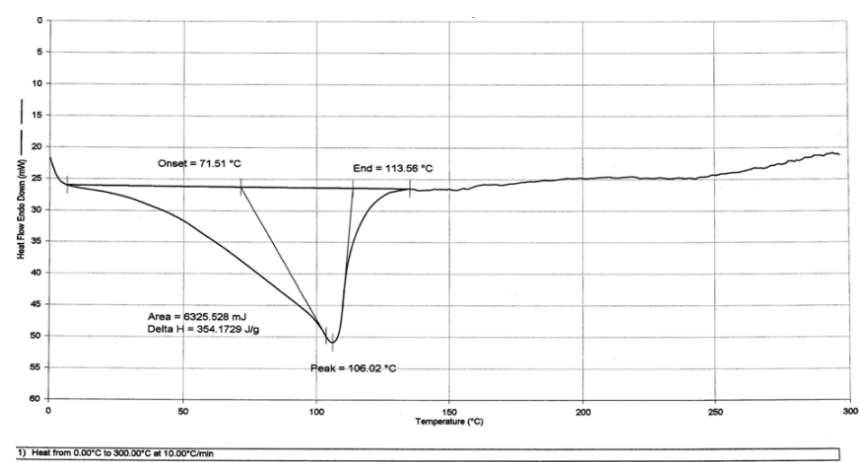

Fig. 1. DSC diagram of pulped wood in $10 \% \mathrm{Na}_{2} \mathrm{SO}_{3}$ $(\mathrm{w} / \mathrm{w})$ bath.

The pulped wood material is mixed with the pure polymer. The compound ratio was $50 \%$ of pulped WF reinforcement and $48 \%$ polyethylene $[12,13]$.

A proper die-head design with the screw geometry was made on the basis of the rheological formation and physical characteristics of the used materials and compounder capabilities, like flow rate and spin pump power. The main body of the extruder die consists of an adapter, separators and upper and lower halves which are shown as the exploded view in Fig. 2.

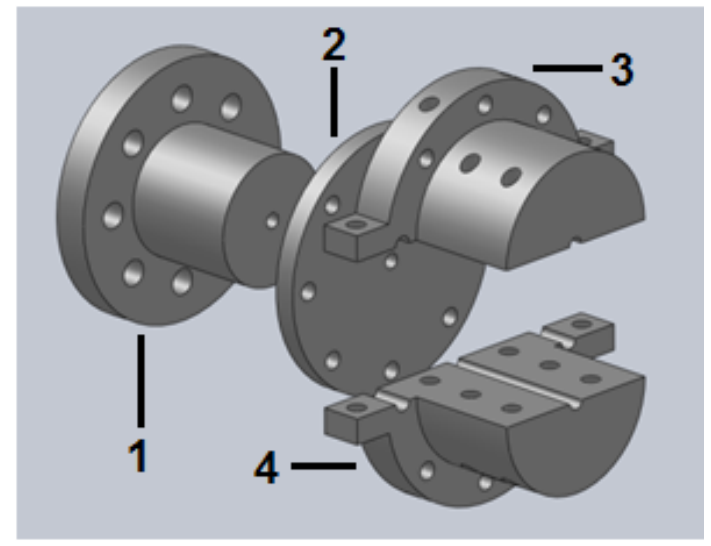

Fig. 2. Exploded view of the instrumented die-head design: 1-adapter, 2-separator, 3-upper halve, 4-lower halve.

After mechanical mixing, the mixture was transferred to the die-head assembled single-screw compounding extruder. Designs of wood and polymer feeding sections, heating and distributing parts are considered for a compounder type mixing compounding extruder with an adapted melt pump system for the compression. The barrel has a diameter of $30 \mathrm{~mm}$, a length of $800 \mathrm{~mm}$ and consists of six zones with separate temperature control units. The stable thermal conditions employed for composite material production are $120^{\circ} \mathrm{C}, 130^{\circ} \mathrm{C}, 140^{\circ} \mathrm{C}$, $140^{\circ} \mathrm{C}, 130^{\circ} \mathrm{C}, 120^{\circ} \mathrm{C}$ at the zones respectively. The screw speed was set to $110 \mathrm{rpm}$ at $20 \mathrm{~Hz}$ frequency for all trials and the machine torque was changed between $0.37-0.57 \mathrm{Nm}$ during the processes.

Schematic illustration of the designed compounding extruder is given in Fig. 3. The pulped and dried WF is delivered to the fluidized bed by the screw in the first feed hopper to mix with polyethylene. After that, polyethylene and WF are mixed homogeneously by the screw at lower squeezing and at higher mixing capabilities. Finally the mix is pressurized by a gear pump to manufacture the final circular bar profiles.

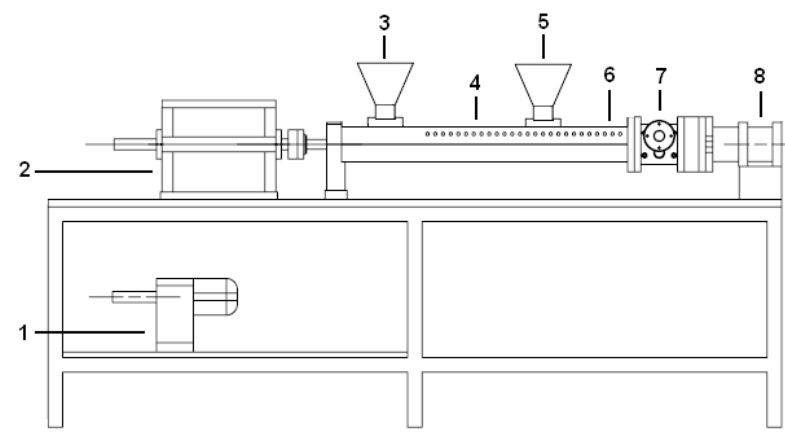

Fig. 3. Schematic illustration of compounding extruder: 1-electrical motor, 2-reduction gear, 3-first feed hopper, 4-single screw, 5-second feed hopper, 6-barrel, 7-spin pump, 8-extrusion die [13].

\section{Results and discussion}

The tensile tests were conducted on the produced wood-polymer composite. The tests were carried out at room temperature on Schimadzu, Japan, AG-X type tensile tester with a $100 \mathrm{kN}$ load cell and a universal extensometer [14].

It is observed that, mechanical qualifications of the produced WF reinforced polymer composite are improved remarkably compared to pure polyethylene. Tensile strength is increased by $67 \%$ against the pure polyethylene. Besides, elongation at tensile break is determined to be 37 times lower than that of the pure polyethylene. The composite was produced at $7.5 \mathrm{mmin}^{-1}$ production rate in average. High production rates and high quality manufacturing was succeeded with the help of pulping process and machine improvements in continuous manufacturing.

TGA results of the WPC are shown in Fig. 4. The upper curve represents $\mathrm{m} / \mathrm{t}$ in the constant heating rate, the middle and the lower curves are the first and the second derivatives of $\mathrm{m} / \mathrm{t}$, respectively. $1.9035 \mathrm{mg}$ $(16.9547 \%)$ mass loss has been recorded at the end of second peak (2). The midpoint of the second peak was recorded at $293.81{ }^{\circ} \mathrm{C}$. The mass loss occurred at 
this temperature represents the degradation of lignocellulosic material. $6.5267 \mathrm{mg}(58.2245 \%)$ mass loss has been recorded at the end of the third peak (3). The midpoint of the third peak was recorded as $474.70^{\circ} \mathrm{C}$. This temperature represents the degradation temperature of polyethylene. Wood-polymer composite includes high percentage of inorganic oxides. An early thermal degradation was observed in composite because of the low enthalpy of the cellulosic wood. Since cellulose based wood fillers have high thermal sensitivity, an accurate temperature control is vital in wood-polymer composite production.

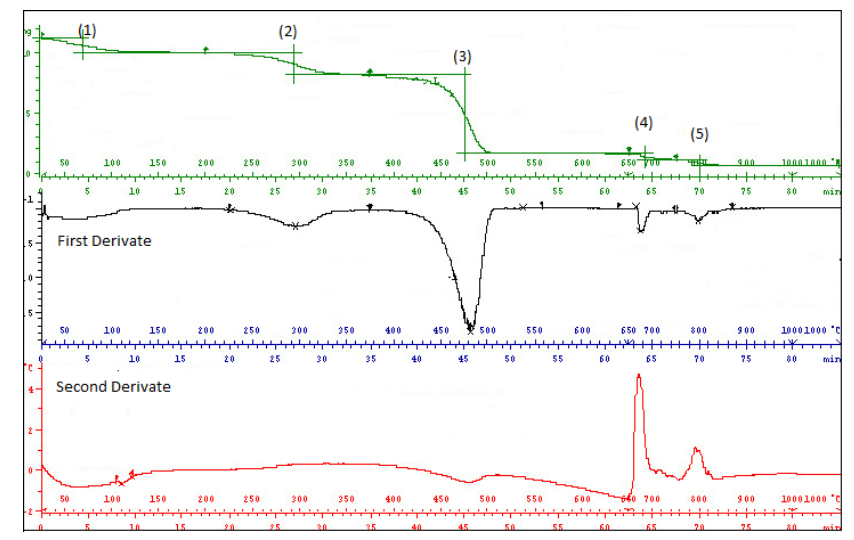

Fig. 4. Thermo gravimetric analysis plot of the composite (50\% WF, $48 \% \mathrm{LDPE})$.

\section{Conclusions}

This work investigates pulping process of WF and WF reinforced composite production. The use of pulped WF has enhanced the mechanical properties of the composite. Pulping is almost inevitable for the reduction of energy costs per product. The machines occupied in the plastic industry can be used in lignocellulosic material reinforced polymer composite production only if they are specifically designed to meet the production requirements of these materials. Moreover, extruders require a high speed mixing capability.

Low viscosity of the material enables processing at low temperatures, requires low pressure and enhances productivity. Furthermore, screw geometry design advantages on homogenize mixing of composites is vital. Researchers should consider proper die design as well. Innovative improvements in screw and die designs increase processing performance of WF reinforced composites allowing higher working pressures and flow rates. Thermal stabilization in composite should be supplied during the process by maximizing thermal heating zones. Moreover, thermal isolation of the barrel can be improved by proper coatings or materials. In this work, high quality manufacturing was succeeded with the help of pelletization process and machine improvements in continuous production.

\section{Acknowledgments}

This work was supported by Science, Industry and Technology Ministry of Turkish Republic, project number 00215.STZ.2007-2.

\section{References}

[1] J. Markarian, Plastics, Additives and Compounding 4(11), 18 (2002).

[2] J. Markarian, Plastics, Additives and Compounding 7(5), 20 (2005).

[3] L. Danyadi, T. Janecska, Z. Szabo, G. Nagy, J. Moczo, B. Pukanszky, Composites Science and Technology 67, 2838 (2007).

[4] A. Bledzki, M. Letman, R. Viksne, L. Rence, Compos. Part A: Appl. Sci. Manuf. 36, 789 (2005).

[5] E. Sykacek, M. Hrabalova, H. Frech, N. Mundigler, Compos. Part A: Appl. Sci. Manuf. 40, 1272 (2009).

[6] I.T. Sarul, A. Akdogan, A. Koyun, J. of Therm. Composite Mater. 23(3), 375 (2010).

[7] J. Markarian, Plastics, Additives and Compounding 8(6), 20 (2006).

[8] M. Bengtsson, M.L. Baillif, K. Oksman, Compos. Part A: Appl. Sci. Manuf. 38, 1922 (2007).

[9] N.S. Cetin, M.H. Alma, M.A. Basturk, Journal of Science and Engineering 3(2), 58 (2001).

[10] K.N. Law, B.V. Kokta, C.B. Mao, Bioresource Technology 77, 1 (2001).

[11] M. Akhtar, G. Scott, R. Swaney, D. Shipley, Res. Cons. and Recycl. 28, 241 (2000).

[12] A. Akdogan, A.S. Vanli, J. of Therm. Composite Mater. 26(9), 1237 (2013).

[13] A. Akdogan and A.S. Vanli, Wood-Reinforced Polymer Composites, Wood in Civil Engineering, Dr. Giovanna Concu (Ed.), InTech 2017.

[14] ISO 527-2: 2012. Plastics - Determination of Tensile Properties - Part 2: Test Conditions for Moulding and Extrusion Plastics. 